\title{
Orthotopic Liver Transplantation in Children: Two-Year Experience with 47 Patients
}

\author{
J. Cartton Gartner, Jr, MD, Basil J. Zitelli, MD, J. Jeffrey Malatack, \\ MD, Byers W. Shaw, MD, Shunzaburo Iwatsuki, MD, and \\ Thomas E. Starzl, MD
}

From the Department of Pediatrics and Surgery, The University of Pittsburgh Health Center, University of Pittsburgh, Pittsburgh

\begin{abstract}
During a 24-month period (May 1981 to May 1983), 47 pediatric patients (ranging in age from 7 months to 18 years) underwent orthotopic liver transplantation using cyclosporine and prednisone. Major indications were biliary atresia/hypoplasia, and metabolic liver disease. Thirty-two of 138 patients evaluated for the procedure died prior to transplantation. Thirty patients are alive from 6 to 29 months later including $7 / 15$ patients who required retransplantation. Twenty-one of $32 \mathrm{pa}-$ tients are alive at 1 year following initial transplantation. All 30 survivors are clinically well and living at home; only one has an abnormal bilirubin level. Serious, lifethreatening medical and surgical complications were common during the early months following transplantation. With one exception, deaths and major rejection episodes occurred early (before 120 days). All survivors are relieved of the stigmata of chronic liver disease, and many have demonstrated catch-up growth. Liver transplantation is an effective treatment for end-stage pediatric liver disease. Pediatrics 1984;74:140-145; transplantation, liver disease, biliary atresia, $\alpha$-1-antitrypsin, hepatic failure.
\end{abstract}

After a series of initial failures, the first successful human liver transplantation took place in 1967

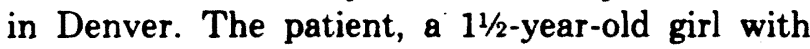
hepatocellular carcinoma, lived for more than 1 year before dying from metastases. ${ }^{1}$ Since that time, more than 400 transplantations have been performed throughout the world..$^{1-7}$ Prior to 1980 , survival at 1 year averaged $30 \%$ with an excellent longterm outlook for those who had normal liver function at 1 year after transplantation. With the intro-

Received for publication Dec 20, 1983; accepted Feb 6, 1984 Reprint requests to (J.C.G.) Children's Hospital of Pittsburgh, 125 DeSoto St, Pittsburgh, PA 15213.

PEDIATRICS (ISSN 0031 4005). Copyright « 1984 by the American Academy of Pediatrics. duction of cyclosporine in the autumn of $1980,8,9$ clinical trials with this drug were initiated. ${ }^{10,11}$ Preliminary success with a cyclosporine/steroid combination led us to consider treating a larger group of children. From May 1981 to May 1983, 47 patients underwent orthotopic liver transplantation at the Children's Hospital of Pittsburgh. The results of this treatment are reported here.

\section{PATIENTS AND METHODS}

Patients were examined for the procedure during a short hospital stay (average 4 days) after referral from their primary physician. Preoperative evaluation emphasized anatomic suitability (patency and size of portal vein), confirmation of diagnosis, and current status (progression of hepatic disease, a search for other major systemic disease, associated vitamin and nutritional deficiencies and base-line assessment of growth, development, and family situation). During the 2 years, 138 patients were evaluated, but 18 were deemed unsuitable, mainly because of anatomic abnormalities (usually vascular), disease of other organ systems which precluded transplantation (ie, severe primary renal disease or severe hepatogenic cyanosis), or lack of severity of underlying disease. Of the remaining patients, 47 children, ranging in age from 7 months to 18 years, had the procedure. Thirty-two children died prior to transplantation and 41 are currently awaiting grafts. Average waiting period from the time of evaluation to transplant was 71 days, with a range of 5 to 330 days.

Candidates for the procedure were selected based on the poor prognosis of their liver disease and included patients with liver failure (manifested by decreasing synthetic function, gastrointestinal bleeding, and encephalopathy ${ }^{12}$ ), patients with liver diseases that have a well-defined progressive course 
(eg, familial cholestasis ${ }^{13.14}$ or biliary atresia with icterus post portoenterostomy ${ }^{16}$ ), and patients with severe hepatic-based metabolic diseases (eg, $\alpha-1$ antitrypsin deficiency with progressive liver disese and other metabolic disease with secondary tumors, such as tyrosinemia $\left.{ }^{16-18}\right)$. Patients with questionable indications were often followed and made candidates for transplantation when their disease showed progression despite medical intervention. We did not include patients with primary malignant tumors because of organ shortage and the high recurrence rate reported previously. ${ }^{19,20}$ Matching was done by size and blood group, but no attempt was made to match human lymphocyte antigen (HLA) loci. With rare exceptions, the more critically ill patients were given the highest priority.

Surgical techniques have been modified over many years and this has contributed substantially to improved outlook. ${ }^{7}$ Veno-veno bypass techniques were utilized in several of our patients, but this has not become standard in pedatric patients. ${ }^{21,22}$ The immunosuppression regimen included cyclosporine given intravenously preoperatively $(5 \mathrm{mg} / \mathrm{kg})$, then postoperatively 5 to $7.5 \mathrm{mg} / \mathrm{kg} / \mathrm{d}$ divided every eight to 12 hours, and then orally when tolerated (average $17.5 \mathrm{mg} / \mathrm{kg} / \mathrm{d}$ ) divided every 12 hours. An intravenous burst of steroid was given for five days (usually starting at $100 \mathrm{mg}$ of methylprednisolone), tapered and then switched to oral prednisone at 10 to 20 $\mathrm{mg} / \mathrm{d}$. With the increasing availability of cyclosporine levels measured by high-pressure liquid chromatography ${ }^{23}$ and the evidence of variability of oral absorption, a period of intravenous/oral overlap was initiated in 1983 to maintain adequate levels. We generally accepted trough blood levels between 150 and $500 \mathrm{ng} / \mathrm{mL}$. In several instances, detailed kinetic data were obtained to allow for more precise administration. We did not rigidly adhere to blood levels in patients who were doing well, as the relationship between cyclosporine level and immunosuppression is still under investigation. However, in patients with transplant rejection or toxic side effects, doses were raised or lowered according to blood level.

Growth data included information sent from primary physicians and measurements made at the time of initial evaluation and follow-up in Pittsburgh; patients were measured supine with tape measure until age 3 years and then standing on a standard metal scale. More recent follow-up evaluations have included statiometer measurements.

Rejection was characterized by rising transaminase, bilirubin, and canalicular enzyme levels often associated with fever, malaise, and hepatomegaly. Attempts were made to eliminate other conditions such as obstruction or ischemia, but occasional overlap did occur. Rejection episodes were variable in severity, and several features could be missing or prominent in an individual patient. ${ }^{6.7}$ Standard treatment included intravenous steroid boluses in high doses usually with a five-day increase and tapering of oral prednisone (recycle). Liver biopsy was reserved for patients who did not respond quickly to antirejection therapy or for those with a high suspicion of other disorders (eg, viral infection or cholangitis). Pathologic changes are currently under study, but the features most consistently seen in children who responded to antirejection therapy were (1) lymphocyte infiltration of the portal areas, (2) hepatocyte necrosis at the limiting plate, and (3) epithelial damage to small bile ducts.

Patients are referred to by orthotopic transplant (OT) number based on sequential procedures in the Denver-Pittsburgh series in order to make identification easier in subsequent publications. The survival curve was derived by using standard methods of life table analysis. ${ }^{24}$ Patients are considered as a group undergoing transplantation and are not withdrawn when retransplantation is required.

\section{RESULTS}

\section{Indications, Operations, and Current Status}

The indications for transplantation are summarized in Table 1. Extrahepatic biliary atresia and biliary hypoplasia (paucity of intrahepatic bile ducts) accounted for nearly half of the 47 patients (22 patients). The other large group included 13 children with metabolic disorders; there were eight with $\alpha$-1-antitrypsin deficiency (and two deaths), two with Wilson's disease (one death), and one each with type 1 glycogen storage disease, hereditary tyrosinemia/hepatoma, and sea-blue histiocyte/hepatoma syndrome, respectively (no deaths).

During the study period, nearly one third of the 47 patients required repeat transplantation; $13 \mathrm{pa-}$ tients received two grafts and two received three grafts for a total of 64 grafts. Eleven of the initial retransplantation procedures were done within the

TABLE 1. Indications for Transplantation

\begin{tabular}{lcc}
\hline & $\begin{array}{c}\text { No. of } \\
\text { Patients }\end{array}$ & $\begin{array}{c}\text { No. of } \\
\text { Deaths }\end{array}$ \\
\hline Biliary atresia & 19 & 7 \\
Biliary hypoplasia & 3 & 2 \\
Metabolic diseases & 13 & 3 \\
Familial cholestasis & 5 & 2 \\
Chronic active hepatitis & 4 & 2 \\
Choledochal cyst/cirrhosis & 1 & 1 \\
Neonatal hepatitis & 1 & \\
Benign liver tumor & 1 & \\
Total & 47 & 17 \\
\hline
\end{tabular}


first postoperative month; the others were scattered up to 244 days later. Third grafts were done at 61 and 291 days. Graft survival is as follows: 23/47 first grafts (49\%), 6/15 second grafts (40\%), and $1 /$ 2 third grafts $(50 \%)$. The current survival rate for those with repeat transplantation is $47 \%(7 / 15)$, in contrast to the overall rate of $64 \%$.

Thirty of the 47 patients are currently surviving 6 to 29 months after surgery with an average followup period of 12 months. Twenty-one of 32 patients are well 1 year after initial transplantation. Current status of graft function for the 30 surviving patients is excellent for 28 (bilirubin, 0.2 to $1.1 \mathrm{mg} / \mathrm{dL}$; SGPT, 12 to $100 \mathrm{IU} / \mathrm{mL}$ ) and good for two (bilirubin, 0.7 to $2.6 \mathrm{mg} / \mathrm{dL}$; SGPT, 79 to $170 \mathrm{IU} / \mathrm{mL}$ ). All patients are living at home, and all are clinically well. One child has resolving, mild chronic rejection, which occurred after immunosuppression was reduced following development of a small-bowel lymphoproliferative disorder associated with an increase in antibodies to the Epstein-Barr virus. ${ }^{25,26}$ There is no sign of tumor 10 months later. Another child has developed mild, biopsy-proven rejection recently as cyclosporine dose was reduced, although her bilirubin level remains normal.

Immunosuppressive medication averaged $15 \mathrm{mg} /$ $\mathrm{kg} / \mathrm{d}$ of cyclosporine and $0.3 \mathrm{mg} / \mathrm{kg} / \mathrm{d}$ of prednisone in the 30 survivors. By 1 year after transplantation, daily doses of cyclosporine averaged $11 \mathrm{mg} / \mathrm{kg}$ and prednisone $5 \mathrm{mg} / \mathrm{d}$.

\section{Deaths}

A survival curve for the entire group is shown in the Figure. Most deaths occurred within 1 month and all except one occurred within 120 days of the initial operation. There were no deaths during surgery; four deaths occurred in the week following initial surgery, five deaths in the second, and one death each in the third and fourth weeks and first and second postoperative months. Three patients died in the third month, and one died at $91 / 2$ months after surgery. Deaths were multifactorial, and in many cases it was impossible to choose a single cause. Infection often supervened in cases of chronic rejection or vascular occlusion. We have listed primary and secondary causes of death in Table 2. Three patients died due to complications of transplant rejection and one (patient OT 214) had a segmental portal vein occlusion as well. Infections were terminal events in all three patients. Preexisting portal vein thrombosis (OT 220) and absent superior vena cava (OT 233) precluded survival in two patients, and major postoperative vascular occlusions (one portal vein [OT 259] and one hepatic artery [OT 267]) were lethal in two others. In two children, death was caused by bacterial

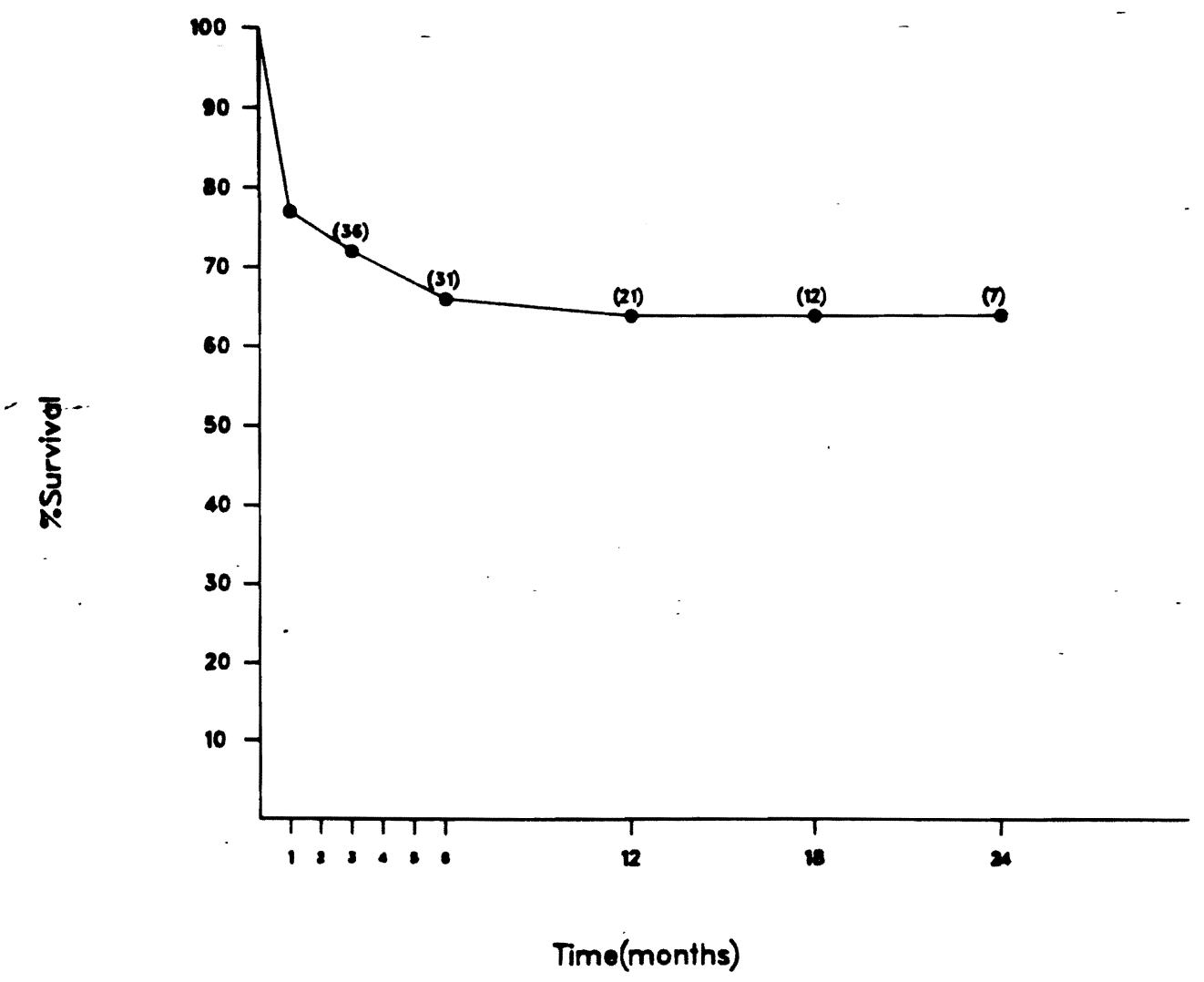

Figure. Survival rate following liver transplantation. Values in parentheses represent patients followed for time indicated. 
TABLE 2. Primary and Secondary Factors in 17 Deaths

\begin{tabular}{lcc}
\hline & Primary & Secondary \\
\hline Rejection & 3 & 2 \\
Vascular anomalies, preoperative & 2 & 1 \\
Vascular complications (surgical) & 2 & 1 \\
Infection & 3 & 4 \\
Massive liver infarction (early) & 3 & $\ldots$ \\
$\quad$ with patent vessels (late) & 2 & $\ldots$ \\
Cerebrovascular accident/edema & 2 & $\ldots$ \\
\hline
\end{tabular}

sepsis (OT 201 and OT 228), but problems with biliary anastomosis may have contributed to abscess and sepsis in one of these. One patient died of complications of cytomegalovirus pneumonia More difficult to explain are the deaths of five patients with massive hepatic necrosis and patent vascular anastomoses. Three deaths (OT 265, OT 271, and OT 279) occurred just after transplantation and may have represented defective organs. The other deaths (OT 232 and OT 240) occurred approximately 11 days later and may have been related to rejection-induced ischemia. One of these later events may be related to preexisting vascular anomalies and poor blood flow (absent inferior vena cava, preduodenal portal vein, and abnormal hepatic artery takeoff). ${ }^{27}$ The primary cause of death in two patients was a CNS catastrophe. A massive cerebrovascular accident in one patient (OT 203) followed a third transplantation; irreversible hepatogenic cyanosis may have contributed to this event. The other patient (OT 284) had acute cerebral edema while undergoing dialysis after successful retransplantation.

\section{Complications in Survivors}

Complications in the 30 survivors were multiple as could be suspected from the average hospital stay of 54 days. Because minor complications occurred frequently, we chose to look at major, lifethreatening ones with onset occurring either before 2 months (early) or after 2 months (late) and usually following discharge from the hospital. This demarcation was chosen because most survivors were discharged and clinically well at 2 months after transplantation.

Early Complications. Early hypertension was almost uniform, but transient, in $29 / 30$ survivors allowing discontinuation of therapy by 3 months after surgery. Hypertension remains unexplained but was also seen in the precyclosporine era. ${ }^{6}$ Five patients had hypertensive seizures despite institution of therapy. Oral captopril was useful in difficult cases. Rejection episodes (21/30 patients) frequently occurred early and usually responded to increased immunosuppression. Serious, life-threatening infections occurred in eight patients. Most episodes were viral: herpes virus (one patient), adenovirus (two patients), and cytomegalovirus (two patients). There were also two major fungal (Candida sp) and four major bacterial infections, along with numerous local wound infections. Biliary tract complications occurred in 5/30 patients; these required drainage after leakage in three patients and early revision of the anastomosis in two. Prolonged tracheostomy (more than 1 month) was required in four patients. Vascular thrombosis (requiring retransplantation) occurred in three patients. Two patients had insulin-dependent, but transient, diabetes mellitus, presumably from steroid therapy.

Late Complications. Episodes of rejection were less frequent and generally less severe after 2 months, but did occur in seven patients. These episodes were easily controlled with adjustments in immunosuppressive therapy. Complete portal vein occlusion with bleeding esophageal varices occurred in two patients, both of whom had previous portocaval shunts. Remarkably, both patients demonstrated hepatopedal flow to the grafted liver through new collaterals, and both maintained normal liver function. One patient underwent successful distal splenorenal shunt (Warren procedure) for recurrent bleeding despite sclerotherapy, and the other patient's condition is stable after sclerotherapy. Two patients developed splenomegaly and hypersplenism from portal vein stricture with successful revision in one patient, and slow, asymptomatic improvement in the other. Biliary tract stricture with obstruction developed late in two patients. It was successfully treated in one patient, and the other developed hepatic abscess following surgery but eventually underwent successful retransplantation. Later in recovery, two patients developed hypertension related to steroid and cyclosporine toxicity. Pneumocystis carinii pneumonia was documented by open lung biopsy in one child and presumed in another because there was an appropriate response to trimethoprim/sulfamethoxazole. One patient developed pseudotumor cerebri with unilateral visual impairment, possibly related to steroid reduction. Pressure has returned to normal after lumboperitoneal shunt. The patient with seablue histiocyte syndrome with progressive neurologic deterioration and a small hepatoma is now in stabilized condition with improved ambulation, but there are storage cells in the transplanted liver. ${ }^{28}$ One patient developed a lymphoproliferative disorder.

\section{Growth, Development, and Quality of Life}

Growth data are available in 24 patients with follow-up of at least 6 months. Two patients in the series are fully grown"adolescents and have re- 
mained the same height. Of the others, $11 / 22$ have demonstrated catch-up growth, crossing percentile lines. All but one of the other 11 patients have maintained a normal growth rate at the preoperative percentile, although several have growth rates below and parallel to the fifth percentile. The child with the sea-blue histiocyte syndrome who was treated for presumed rejection with high-dose steroid for several months and whose repeat liver biopsy showed recurrent storage cells has had growth deceleration.

All 30 children are living at home with previous caretakers; psychological and developmental follow-up information is being obtained. Pruritus, xanthomata, icterus, organomegaly, clubbing, and malnutrition have improved or disappeared. Nearly all patients have had increased energy, and schoolaged children have returned to regular classes. However, the stress of recurrent esophageal varices and worry about retransplantation have produced anxiety and depression in several of our patients. Older children, in general, have had more anxiety about the future, and several fear rejection of the graft.

\section{DISCUSSION}

The previous high operative mortality and complex nature of liver transplantation made it a rare procedure, especially in the pediatric age group. Eighty-six pediatric patients received grafts in Denver, by far the major series, from 1963 to 1979 in the precyclosporine era with a current survival rate of $21 \%$ overall. ${ }^{7}$ The average survival in the latter part of the series was $30 \%$ overall. The $64 \%$ survival figure in our current series may appear overly optimistic as all patients are not yet 1 year posttransplant. However, only one patient in the series with excellent graft function at 3 months has shown subsequent major rejection; this was the patient with a lymphoproliferative disorder whose immunosuppression therapy had to be reduced. Barring unforeseen new disorders, most of these patients should be long-term survivors. Additional benefits to these children are freedom from chronic disease and a good chance for improved growth.

Although liver transplantation may be used for the treatment of a variety of hepatic diseases, metabolic disorders probably represent the best indications. The operation is often technically easier because of the absence of previous surgery. More important, there is a potential for cure of the metabolic defect as well as the secondary hepatic disease. For example, $\alpha$-1-antitrypsin levels and $\mathrm{Pi}$ type normalize, suggesting that pulmonary disease will no longer be of concern in this condition. Poor quality of life and severe dietary restriction may be reversed in glycogen storage disesae and tyrosinemia.

A striking finding of this series is the efficacy of repeat transplantation. The current survival rate of $47 \%$ for retransplantation is even better than the best overall results from the precyclosporine era. One of our patients is living and well with his third graft.

The price of liver transplantation is a high one for most children. The procedure and postoperative course are characterized by numerous potential lifethreatening complications requiring constant vigilance. The average hospital stay is $\mathbf{5 4}$ days (range 16 to 134 days). Children and families are stressed constantly, as to some extent is the medical staff. From the onset, we were concerned about developmental issues in these children. Experience in renal transplant programs indicated that while excellent graft function was generally associated with good psychological health, emotional difficulties occurred frequently. ${ }^{29,30}$ In contrast to previous studies of liver transplant recipients, ${ }^{31,32}$ we attempted to obtain assessments of emotional and developmental status on all patients, even those without overt problems. Generally, patients with excellent graft function have improved growth and development, but they may need ongoing emotional support. An intensive team effort is absolutely necessary for success, a team that includes nursing, social service, psychiatry, psychology, occupational and play therapy, and others who are aware of the special problems and needs of patients who have received transplants. We believe that with this type of approach, liver transplantation truly represents a major advance in the treatment of pediatric liver disease; it brings together the major advances in surgery, immunology, and pediatric care of the last two decades.

\section{ADDENDUM}

Our experience with 17 additional patients from May 1983 through October 1983 (with at least a 6-month follow-up) justifies continued optimism: All but two have been discharged and are living at home. One patient is still recovering in the hospital; one patient died. Five patients have required retransplantation thus far; one of these was the child who died.

\section{REFERENCES}

1. Starzl TE, Groth CT, Brettschneider L, et al: Orthotopic homotransplantation of the human liver. Ann Surg 1968; 168:392-415

2. Starzl TE, Koep LJ, Halgrimson CG, et al: Fifteen years of clinical liver transplantation. Gastroenterology 1979;77:375388

3. Starzl TE, Koep L, Porter KA, et al: Decline in survival after liver transplantation. Arch Surg 1980;115:815-819 
4. Starzl TE, Iwatsuki S, Klintmalm G, et al: Liver transplantation 1980, with particular reference to cyclosporin $A$. Transplant Proc 1981;13:281-285

5. Starz] TE, Koep LJ, Schroter GPJ, et al: Liver replacement for pediatric patients. Pediatrics 1979;63:825-829

6. Starzl TE: Experience in Hepatic Transplantation. Philadelphia, WB Saunders CO, 1969.

7. Staral TE, Iwatsuki S, Van Thiel D, et al: Evolution of liver transplantation. Hepatology 1982;2:614-636

8. Borel JF, Feurer C, Gubler HU, et al: Biological effects of cyclosporin A: A new antilymphocyte agent. Agents Actions 1976;6:468-475

9. Borel JF, Feurer C, Gubler HU, et al: Effects of the new antilymphocyte peptide cyclosporin $A$ in animals. Immunology 1977;32:1017-1025

10. Starzl TE, Klintman GBG, Porter K, et al: Liver transplantation with use of cyclosporin A and prednisone. $N$ Engl $J$ Med 1981;205:266-269

11. Starzl TE, Iwatsuki S, Malatack JJ, et al: Liver and kidney transplantation in children receiving cyclosporin $A$ and steroids. J Pediatr 1982;100:681-686

12. Houssin D, Franco D, Corlette MB, et al: Criteria for hepatic transplantation in cirrhosis. Surg Gynecol Obstet 1980;151: 30-32

13. Linarelli LG, Williams CN, Phillips, MJ: Bylers disease: Fatal intrahepatic cholestasis. J Pediatr 1972;81:484-492

14. Williams CN, Kaye R, Baker $L$, et al: Progressive familial cholestasis cirrhosis and bile acid metabolism. $J$ Pediatr 1972;81:493-500

15. Altman RP: Biliary atresia. Pediatrics $1981 ; 68: 896-898$

16. Malatack JJ, Finegold DN, Iwatsuki $S$, et al: Liver transplantation for type I glycogen storage disease. Lancet 1983;1:1073-1074

17. Hood JM, Koep LJ, Peters RL, et al: Liver transplantation for advanced liver disease with alpha-1-antitrypsin deficiency. $N$ Engl J Med 1980;302:272-275

18. Zitelli BJ, Malatack JJ, Gartner JC, et al: Orthotopic liver

transplantation in children with hepatic-based metabolic disease. Transplant Proc 1983;15:1284-1287
19. Calne RY: Liver transplantation for liver cancer. World J Surg 1982;6:76-80

20. Iwatsuki S, Klintman GBG, Starzl TE: Total hepatectomy and liver replacement (orthotopic liver transplantation) for primary hepatic malignancy. World J Surg 1982;6:81-85

21. Calne RY, McMaster P, Smith DP, et al: Use of partial cardiopulmonary bypass during the anhepatic phase of orthotopic liver grafting. Lancet 1979;2:612-614

22. Calne RY, Williams $R$, Lindop $M$, et al: Improved survival after orthotopic liver grafting. Br Med J 1981;283:115-118

23. Sawchuck RJ, Cartier LL: Liquid chromatographic determination of cyclosporin $A$ in blood and plasma. Clin Chem 1981;27:1368-1371

24. Colton T: Statistics in Medicine. Boston, Little, Brown \& Co, 1974, chap 9, pp 237-250

25. Hanto DW, Sakamoto K, Purtilo DT, et al: The EpsteinBarr virus in the pathogenesis of post transplant lymphoproliferative disorders. Surgery 1981;90:204-213

26. Bird AG, Britton S: The relationship between Epstein-Barr virus and lymphoma. Semin Hematol 1982;19:285-300

27. Lilly JR, Starzl TE: Liver transplantation in children with biliary atresia and vascular anomalies. $J$ Pediatr Surg 1974:9:707-714

28. Neville BGR, Lake BD, Stephens R, et al: A neurovisceral storage diszase with vertical supranuclear ophthalmoplegia and its relationship to Niemann-Pick disease. Brain 1973; 96:97-120

29. Bernstein DM: After transplantation-The child's emotional reactions. Am J Psychiatry 1977;127:1188-1193

30. Khan AU, Herndon CH, Ahmadian SY: Social and emotional adaptations of children with transplanted kidneys and chronic hemodialysis. Am J_Psychiatry 1971;127:11941198

31. Starzl TE, Koep LJ, Schroter GPJ, et al: The quality of life after liver transplantation. Transplant Proc 1979;11:252256

32. Penn I, Branch D, Olenik D, et al: Psychiatric experience with patients receiving renal and hepatic transplants. Semin Psychiatry 1971;3:133-143 